\title{
Correlation of physical fitness with psychological well-being, stress, and depression in Korean adults
}

\author{
Bogja Jeoung* \\ Department of Exercise Rehabilitation \& Welfare, College of Health Science, Gachon University, Incheon, Korea
}

The purpose of this study was to examine the relationship between physical fitness and psychological well-being, stress, and depression in Korean adults. Participants were 160 adults aged $40-70$ years living in the metropolitan area of Incheon. Results were collected from random sample of main measurements from Incheon fitness center of National Fitness Award Project (2019). We assessed participants using physical fitness test (national fitness award), Psychosocial well-being index short form, Perceived Stress Scale, Geriatric Depression Scale. The data were analyzed Pearson and Spearman rank correlation analysis, and linear was conducted using IBM SPSS Statistics ver. 25.0. The re- sults indicated there were statistically significant associations between psychological well-being and agility, quick response; stress and flexibility; depression and strength endurance strength, body fat. In addition, analysis showed that strength, endurance strength, body fat of physical fitness factors could significantly predict depression, flexibility could significantly predict stress, agility and quick response could significantly predict psychological well-being.

Keywords: Physical fitness, Stress, Depression, Psychosocial well-being

\section{INTRODUCTION}

Physical fitness is the basic ability of motor performance and maintain one's health based on physical function. It is the functional and innate physical ability to respond actively to given stimuli within a given environment. It can also be defined as the ability to utilize the body with optimal efficiency (Blair et al., 1989). While the definitions vary somewhat among scholars, the World Health Organization defines physical fitness as the ability required to perform satisfactorily tasks that involve muscular work under given conditions. Physical fitness can be divided into the physical and mental components. Each component is further divided into fitness for performance and fitness for protection. The former is divided into abilities for the expression, maintenance, and regulation of physical activity; whereas the latter is the ability to sustain health by resisting changes in the environment. Physical fitness can also be divided into health- and skill-related fitness (Becofsky et al., 2015; Blumenthal et al., 2007; Cho et al., 1998).
Meanwhile, aging is related to cognitive decline and increased incidence of chronic diseases, which can cause changes in motor function and decline in physical abilities, activities of daily living, and physical fitness (Aparicio-Ugarriza et al., 2018). Increasing the amount of physical activity and improving physical fitness have been suggested to prevent cognitive decline and increased incidence of chronic disease. Regular and continuous engagement in physical activity is known to have positive effects on physical and mental health. These effects include the enhancement of the physical factors of physical fitness, such as strength, endurance strength, flexibility, agility, balance, and cardiorespiratory endurance, and the mental factors, ultimately leading to psychological stability, happiness, stress relief, and reduction of depression (Becofsky et al., 2015; Blumenthal et al., 2007).

Physical fitness enhancement provides various advantages in terms of health science through engagement in physical activity. Physical fitness and physical activity help reduce the relative risk of metabolic and cardiovascular diseases (Williams, 2001). In par-
${ }^{*}$ Corresponding author: Bogja Jeoung (iD https://orcid.org/0000-0002-7144-6179 Department of Exercise Rehabilitation \& Welfare, College of Health Science, Gachon University, 191 Hambangmoe-ro, Yeonsu-gu, Incheon 21936, Korea E-mail: bogja05@gachon.ac.kr

Received: June 8, 2020 / Accepted: July 2, 2020
This is an Open Access article distributed under the terms of the Creative Commons Attribution Non-Commercial License (https://creativecommons.org/licenses/by-nc/4.0/) which permits unrestricted non-commercial use, distribution, and reproduction in any medium, provided the original work is properly cited. 
ticular, high levels of cardiorespiratory endurance in adults reduce mortality (Lee et al., 1999). Moreover, high strength reduces the risk of metabolic and cardiovascular diseases (Jurca et al., 2004). As such, physical fitness is known as a powerful predictor for reducing the prevalence and mortality of metabolic syndrome, type II diabetes, and cardiovascular disease (Blair et al., 1989, 1996; Farrell et al., 1998). Erickson et al. (2014) demonstrated the association among physical activity, cardiorespiratory endurance, and gray matter volume.

In terms of mental health, Yamagata et al. (2013) found that among the components of physical fitness, individuals with higher levels of leg strength and cardiorespiratory endurance are less likely to have symptoms of depression. Ernst et al. (2006) reported the correlation between cardiorespiratory endurance and depression, whereas Vogelzangs et al. (2008) demonstrated the association between body fat and depression.

As such, physical fitness has continued to draw attention as a major research topic for investigators in exercise science, who, based on such findings, have emphasized the importance of cardiorespiratory endurance and strength enhancement (Chen et al., 2006; Jurca et al., 2004; Polak et al., 2006). These previous studies are mostly about increasing the amount of physical activity, changing the level of physical fitness, metabolic syndrome, cardiovascular diseases, and depression, and are limited to the physical fitness factors of cardiorespiratory endurance and strength. Meanwhile, the effects of the other factors of physical fitness, including flexibility, agility, quick response, balance, and body fat, on stress, depression, and mental health have not been examined. The present study thus aimed to analyze the correlation of physical fitness factors with and their effects on psychological well-being, depression, and stress in Korean adults in order to provide basic data for the development of exercise programs that can enhance the physical fitness factors for maintaining good mental health.

\section{MATERIALS AND METHODS}

\section{Participants}

A total of 160 adults aged 40-70 years living in the metropolitan area of Incheon participated in this study. These are people who voluntarily participated in the Incheon Fitness Center of the National Sports Awards Project (2019). All potential participants received a comprehensive explanation of the proposed study. They underwent tests for physical fitness, psychological well-being, stress, and depression. The general characteristics of the partici-
Table 1. Demographic characteristics of the participants $(n=160)$

\begin{tabular}{lc}
\hline Characteristic & Value \\
\hline Sex & \\
Male & $38(23.8)$ \\
Female & $122(76.2)$ \\
Age (yr) & $54.20 \pm 8.4$ \\
Height (cm) & $157.6 \pm 6.9$ \\
Weight $(\mathrm{kg})$ & $61.2 \pm 10.0$ \\
Body mass index (kg/m²) & $24.49 \pm 3.1$ \\
Strength (kg) & $22.92 \pm 6.0$ \\
Endurance strength (time) & $20.13 \pm 12.1$ \\
Cardiorespiratory fitness (time) & $17.9 \pm 9.7$ \\
Flexibility (cm) & $13.9 \pm 8.3$ \\
Agility (sec) & $14.4 \pm 2.4$ \\
Quick response (cm) & $130.17 \pm 24.3$ \\
Depression (score) & $5.93 \pm 2.0$ \\
Stress (score) & $19.6 \pm 4.2$ \\
Psychological well-being (score) & $47.6 \pm 8.0$ \\
\hline
\end{tabular}

Values are presented as number (\%) or mean \pm standard deviation.

pants are shown in Table 1.

\section{Physical fitness test}

For the physical fitness test, I used the method of measurement currently used in the National Fitness Award (NFA) program and assessed the following subcomponents. Strength was measured as grip strength; endurance strength was assessed by sit-ups; and cardiorespiratory endurance was assessed by a 20 -m shuttle run to the NFA theme song and measured as the number of laps. Flexibility was measured as the sit-reach result $(\mathrm{cm})$, whereas agility was assessed by four 10-m shuttle runs (total of $40 \mathrm{~m}$ ) and measured using a stopwatch. For the quick response measurement., the participants were asked to perform the standing long jump, and jump distance was measured in $\mathrm{cm}$. Body mass index (BMI) was measured using a height and weight scale. Prior to the physical fitness test, the participants performed warm-up exercises including simple calisthenics, such as stretching and running. They were also informed about the testing method and precautions.

\section{Psychosocial Well-being Index Short Form}

For the psychological well-being test, we used the 18-item Psychosocial Well-being Index Short Form (PWI-SF), which was adapted from the General Health Questionnaire (GHQ-60 by Goldberg; Nam et al., 2017). The testing form included a 4-point scale ("Always," "Often," "Sometimes," and "Never"), and each item was scored from 0 to 3, which was reversed for negatively worded items. A lower total score indicated better psychosocial 
health status. The reliability of the PWI-SF test form used in this study was confirmed, with the Cronbach alpha of 0.830 .

\section{Perceived Stress Scale}

The Perceived Stress Scale (PSS) was developed by Cohen (Nam et al., 2017), I used the questionnaire, which consists of 10 items to assess for overall awareness of stress that threatens health or requires another response in one's daily living. The test form uses a 5-point scale ("Never," "Almost never," " Sometimes," "Quite often," and "Very often"), with each item scored from 0 to 4 . The PSS has a score range of 1 to 50 , and items $4,5,7$, and 8 are reverse-scored. A higher score indicated higher perceived stress, for the average adult. In this study, the Cronbach alpha was 0.753 .

\section{Geriatric Depression Scale}

For the depression test form, I used the Korean version of the Geriatric Depression Scale (GDS), a depression diagnostic scale based on DSM-III-R (Diagnostic and Statistical Manual of Mental Disorders, Third Edition, Revised), developed by Yesavage (1988). The participants were asked to mark "Yes" if they thought the statement described their condition well and "No" if not. For items $1,5,7,11$, and 13 , "No" was scored 1 , whereas for all other items, "Yes" was scored 0 . The reliability of the GDS version used in this study was confirmed, with Cronbach alpha of 0.803 .

\section{Data analyses}

IBM SPSS ver. 25.0 (IBM Co., Armonk, NY, USA) was used in the data analyses. I used descriptive statistics, according to the study's aim. Pearson and Spearman rank correlation analyses were performed to examine the correlations of physical fitness with stress, mental health, and depression. Linear regression was conducted for physical fitness and stress, mental health, depression scores, and physical fitness factors that showed significant correlations, in order to analyze their effects on physical fitness factors. The level of significance was set at $P<0.05$.

\section{RESULTS}

This study analyzed the correlation between the physical fitness factors and psychological well-being experienced in the past few weeks, perceived stress in the past month, and depression. As shown in Table 2, depression was correlated with strength ( $r=$ $0.242, P<0.01)$, endurance strength $(r=0.231, P<0.05)$, and $\operatorname{BMI}(r=0.261, P<0.05)$, whereas stress was correlated with flexibility $(r=0.192, P<0.05)$. Psychological well-being was correlated with agility $(r=-0.276, P<0.01)$ and quick response $(r=0.256$, $P<0.05)$.

Among the physical fitness factors that showed a correlation with depression, we performed regression analysis on the effect of strength, endurance strength, and BMI on depression. The score for depression was predicted to decrease by $-0.24(P<0.01)$ when the strength score increased by 1 (coefficient of determination, $\left.R^{2}=0.050\right)$. Depression was predicted to decrease by $-0.231(P<$ $0.05)$ when the endurance strength score increased by $1\left(R^{2}=0.043\right)$ (Table 3).

The linear regression analysis indicated that the stress score was predicted to decease by $-0.192(P<0.05)$ when the flexibility score increased by $1\left(R^{2}=0.028\right)$ (Table 4$)$.

Moreover, we found correlations between physical fitness factors and psychological well-being, agility, and quick response. The re-

Table 2. Correlation of physical fitness with psychological well-being, stress, and depression

\begin{tabular}{lccccccc}
\hline Variable & Grip strength & Endurance strength & Cardiorespiratory fitness & Flexibility & Agility & Quick response & Body mass index \\
\hline Depression & $-0.242^{* *}$ & $-0.231^{*}$ & -0.026 & -0.004 & 0.102 & -0.163 & $0.261^{*}$ \\
Stress & -0.081 & 0.146 & -0.177 & $0.192^{*}$ & 0.027 & 0.172 & 0.121 \\
Psychological well-being & 0.004 & 0.177 & -0.046 & -0.176 & $-0.276^{* *}$ & $0.256^{*}$ & -0.200 \\
\hline
\end{tabular}

${ }^{*} P<0.05$. ${ }^{* *} P<0.01$.

Table 3. Regression analysis of strength, endurance strength, body mass index, and depression

\begin{tabular}{lccccc}
\hline Variable & $b$ & $\beta$ & $R^{2}$ & $T$ & $P$-value \\
\hline Strength & -0.087 & -0.242 & 0.050 & -2.67 & $0.009^{* *}$ \\
Endurance strength & -0.052 & -0.231 & 0.043 & -2.3 & $0.024^{*}$ \\
Body mass index & 0.313 & 0.261 & 0.060 & 2.41 & $0.018^{*}$ \\
\hline
\end{tabular}

${ }^{*} P<0.05$. ${ }^{* *} P<0.01$.
Table 4. Regression analysis of flexibility and stress

\begin{tabular}{cccccc}
\hline & $b$ & $\beta$ & $R^{2}$ & $T$ & $P$-value \\
\hline Flexibility & -0.095 & -0.192 & 0.028 & -2.09 & $0.039^{*}$ \\
\hline
\end{tabular}

${ }^{*} P<0.05$. 
Table 5. Regression analysis of agility, quick response, and psychological well-being

\begin{tabular}{lccccl}
\hline & $\mathrm{b}$ & $\beta$ & $R^{2}$ & $T$ & $P$-value \\
\hline Agility & 0.060 & 0.256 & 0.055 & 2.511 & $0.014^{*}$ \\
Quick response & 0.829 & 0.276 & 0.066 & 2.720 & $0.008^{* *}$ \\
\hline
\end{tabular}

${ }^{*} P<0.05$. ${ }^{*} P<0.01$.

sults of linear regression indicated that the psychological well-being score was predicted to increase by $0.276(P<0.05)$ when the agility score increased by $1\left(R^{2}=0.055\right)$. The psychological wellbeing score was also predicted to increase by $0.276(P<0.01)$ when the quick response score increased by $1\left(R^{2}=0.066\right)$ (Table 5). Significant differences were observed in both predictions.

\section{DISCUSSION}

Regarding mental health and exercise, researchers have argued that exercise brings self-awareness, positive changes in well-being and confidence, cognitive enhancement, emotional changes, tension relief, elimination of depression and anxiety emotions, enhanced mental well-being, and increased social contact and pleasure, whereas regular exercise contributes to improvement in physical fitness (Baceviciene et al., 2019).

In the present study, I analyzed the correlation between each physical fitness factor and psychological well-being, stress, and depression in adults aged 40 years or older. I found correlations between psychological well-being and, of the physical fitness factors, agility, and quick response, which showed effects on the former. In addition, depression was correlated with and affected by strength, endurance strength, and body fat. The study by Lee et al. (1999), although conducted among Korean adolescents, demonstrated the association between mental health and the physical fitness factors of endurance strength and agility. A study conducted in postmenopausal women reported an association between mental health and balance (Moratalla-Cecilia et al., 2016). In a study of depression and physical fitness factors, Ho et al. (2008) reported an association between depression and body fat in adult of china. A study conducted in adults in Sweden reported the effect of cardiorespiratory endurance on depression (Gerber et al., 2013). In Korean old people, depression has been demonstrated to correlate with strength, cardiorespiratory endurance, agility, and balance (Ahn and Kang, 2015).

In the present study, however, I found no correlation between depression and cardiorespiratory endurance; we found a significant correlation among depression, strength, and endurance, consistent with the study by Ahn and Kang (2015) among Korean elderly that showed an association between depression and strength. Despite the contradictory finding that depression and cardiorespiratory endurance are not correlated, previous results have suggested a possible mechanism for how cardiorespiratory endurance can prevent and improve depressive symptoms; it is proposed to have a protective function in psychological and physiological terms. Psychologically, cardiorespiratory improvement through regular exercise increases self-efficacy, self-esteem, and social reinforcement. Physiologically, it increases the amount and activation of major neurotransmitters, including serotonin, epinephrine, and dopamine, is associated with decreased cortisol levels and weakened cardiovascular responses owing to stress, and decreases inflammatory responses. A high cardiorespiratory endurance level is known to increase brain-derived neurotrophic factor and hippocampal neurogenesis (Cotman et al., 2007; Deslandes et al., 2009; Dishman et al., 2006; Ernst et al., 2006). In addition, I analyzed the relation between stress and physical fitness factors and found that, of the physical fitness factors, flexibility affected the decrease in stress. A correlation study of stress and physical fitness factors conducted in Swedish adults reported that cardiorespiratory endurance affects stress (Gerber et al., 2013). Østerås et al. (2017) also reported that strength is associated with stress, whereas Gerber et al. (2013) reported that body fat is associated with stress.

Taken together, stress has been reported to be associated with cardiorespiratory endurance, strength, agility, and body fat, but the present study showed a different result: flexibility affects stress. Therefore, research on the correlation between physical fitness factors and psychological well-being, depression, and stress must continue, as well as meta-analyses based on the results, to develop and implement a program for improving each physical fitness factor, which will contribute to physical fitness and mental health, including improvement in psychological well-being, depression, and stress.

\section{CONFLICT OF INTEREST}

No potential conflict of interest relevant to this article was reported.

\section{REFERENCES}

Ahn JD, Kang H. Physical fitness and serum vitamin D and cognition in elderly Koreans. J Sports Sci Med 2015;14:740-746.

Aparicio-Ugarriza R, Díaz ÁE, Palacios G, Bibiloni MDM, Julibert A, Tur 
JA, González-Gross M. Association between blood marker analyses regarding physical fitness levels in Spanish older adults: a cross-sectional study from the PHYSMED project. PLoS One 2018;13:e0206307.

Baceviciene M, Jankauskiene R, Emeljanovas A. Self-perception of physical activity and fitness is related to lower psychosomatic health symptoms in adolescents with unhealthy lifestyles. BMC Public Health 2019; 19:980.

Becofsky KM, Sui X, Lee DC, Wilcox S, Zhang J, Blair SN. A prospective study of fitness, fatness, and depressive symptoms. Am J Epidemiol 2015;181:311-320.

Blair SN, Kampert JB, Kohl HW 3rd, Barlow CE, Macera CA, Paffenbarger RS Jr, Gibbons LW. Influences of cardiorespiratory fitness and other precursors on cardiovascular disease and all-cause mortality in men and women. JAMA 1996;276:205-210.

Blair SN, Kohl HW 3rd, Paffenbarger RS Jr, Clark DG, Cooper KH, Gibbons LW. Physical fitness and all-cause mortality. A prospective study of healthy men and women. JAMA 1989;262:2395-2401.

Blumenthal JA, Babyak MA, Doraiswamy PM, Watkins L, Hoffman BM, Barbour KA, Herman S, Craighead WE, Brosse AL, Waugh R, Hinderliter A, Sherwood A. Exercise and pharmacotherapy in the treatment of major depressive disorder. Psychosom Med 2007;69:587-596.

Chen LJ, Fox KR, Haase A, Wang JM. Obesity, fitness and health in Taiwanese children and adolescents. Eur J Clin Nutr 2006;60:1367-1375.

Cho MJ, Nam JJ, Suh GH. Prevalence of symptoms of depression in a nationwide sample of Korean adults. Psychiatry Res 1998;81:341-352.

Cotman CW, Berchtold NC, Christie LA. Exercise builds brain health: key roles of growth factor cascades and inflammation. Trends Neurosci 2007;30:464-472

Deslandes A, Moraes H, Ferreira C, Veiga H, Silveira H, Mouta R, Pompeu FA, Coutinho ES, Laks J. Exercise and mental health: many reasons to move. Neuropsychobiology 2009;59:191-198.

Dishman RK, Berthoud HR, Booth FW, Cotman CW, Edgerton VR, Fleshner MR, Gandevia SC, Gomez-Pinilla F, Greenwood BN, Hillman CH, Kramer AF, Levin BE, Moran TH, Russo-Neustadt AA, Salamone JD, Van Hoomissen JD, Wade CE, York DA, Zigmond MJ. Neurobiology of exercise. Obesity (Silver Spring) 2006;14:345-356.

Erickson KI, Leckie RL, Weinstein AM. Physical activity, fitness, and gray matter volume. Neurobiol Aging 2014;35 Suppl 2:S20-28.

Ernst C, Olson AK, Pinel JP, Lam RW, Christie BR. Antidepressant effects of exercise: evidence for an adult-neurogenesis hypothesis? J Psychiatry Neurosci 2006;31:84-92

Farrell SW, Kampert JB, Kohl HW 3rd, Barlow CE, Macera CA, Paffenbarger RS Jr, Gibbons LW, Blair SN. Influences of cardiorespiratory fitness levels and other predictors on cardiovascular disease mortality in men. Med Sci Sports Exerc 1998;30:899-905.

Gerber M, Lindwall M, Lindegård A, Börjesson M, Jonsdottir IH. Cardiorespiratory fitness protects against stress-related symptoms of burnout and depression. Patient Educ Couns 2013;93:146-152.

Ho RC, Niti M, Kua EH, Ng TP. Body mass index, waist circumference, waist-hip ratio and depressive symptoms in Chinese elderly: a population-based study. Int J Geriatr Psychiatry 2008;23:401-408.

Jurca R, Lamonte MJ, Church TS, Earnest CP, Fitzgerald SJ, Barlow CE, Jordan AN, Kampert JB, Blair SN. Associations of muscle strength and fitness with metabolic syndrome in men. Med Sci Sports Exerc 2004; 36:1301-1307.

Lee CD, Blair SN, Jackson AS. Cardiorespiratory fitness, body composition, and all-cause and cardiovascular disease mortality in men. Am J Clin Nutr 1999;69:373-380.

Moratalla-Cecilia N, Soriano-Maldonado A, Ruiz-Cabello P, Fernández MM, Gregorio-Arenas E, Aranda P, Aparicio VA. Association of physical fitness with health-related quality of life in early postmenopause. Qual Life Res 2016;25:2675-2681.

Nam JH, Lim MS, Choi HK, Kim JY, Kim SK, Oh SS, Koh SB, Kang HT. Factors increasing the risk for psychosocial stress among Korean adults living in rural areas: using generalized estimating equations and mixed models. Ann Occup Environ Med 2017;29:53.

Østerås B, Sigmundsson H, Haga M. Physical fitness levels do not affect stress levels in a sample of Norwegian adolescents. Front Psychol 2017;8:2176.

Polak J, Klimcakova E, Moro C, Viguerie N, Berlan M, Hejnova J, Richterova B, Kraus I, Langin D, Stich V. Effect of aerobic training on plasma levels and subcutaneous abdominal adipose tissue gene expression of adiponectin, leptin, interleukin 6, and tumor necrosis factor alpha in obese women. Metabolism 2006;55:1375-1381.

Vogelzangs N, Kritchevsky SB, Beekman AT, Newman AB, Satterfield S, Simonsick EM, Yaffe K, Harris TB, Penninx BW. Depressive symptoms and change in abdominal obesity in older persons. Arch Gen Psychiatry 2008;65:1386-1393.

Williams PT. Physical fitness and activity as separate heart disease risk factors: a meta-analysis. Med Sci Sports Exerc 2001;33:754-761.

Yamagata E, Yamada Y, Sugihara Y, Komatsu M, Kimura M, Okayama Y. Physical fitness and depression symptoms in community-dwelling elderly women. Nihon Koshu Eisei Zasshi 2013;60:231-240.

Yesavage JA. Geriatric Depression Scale. Psychopharmacol Bull 1988;24: 709-711. 